\title{
Prevalence of foot lesions in Québec dairy herds from 2015 to 2018
}

\author{
Juan C. Arango-Sabogal, ${ }^{1,2} \odot$ André Desrochers, ${ }^{1} \odot$ René Lacroix, ${ }^{3} \odot$ Anne-Marie Christen, ${ }^{3} \odot$ \\ and Simon Dufour ${ }^{2,4 *}$ (i) \\ ${ }^{1}$ Département de sciences cliniques, Faculté de médecine vétérinaire, Université de Montréal, Saint-Hyacinthe, QC, J2S 8H5, Canada \\ ${ }^{2}$ Regroupement FRQNT Op+Lait, Saint-Hyacinthe, QC, J2S 2M2, Canada \\ ${ }^{3}$ Lactanet, Sainte-Anne-de Bellevue, QC, H9X 3R4, Canada \\ ${ }^{4}$ Département de pathologie et microbiologie, Faculté de médecine vétérinaire, Université de Montréal, Saint-Hyacinthe, QC, J2S 2M2, Canada
}

\begin{abstract}
Our first objective was to estimate the prevalence of foot lesions by type of milking system in dairy cows examined during regular hoof-trimming sessions between 2015 and 2018 in Québec dairy herds. A secondary objective was to describe the effect of day-to-day variation, cow, and herd characteristics on the prevalence of foot lesions. Data included 52,427 observations (on a cow during a specific trimming session) performed on 28,470 cows ( $\geq 2$ yr old) from 355 herds. Only observations from trimming sessions in which $\geq 90 \%$ of the lactating herd was trimmed were considered. Lesions were recorded at the hoof level by 17 trained hoof trimmers between March 23, 2015, and July 10, 2018, using a computerized recording system. Hoof-level information was then matched with cow information and centralized at the Eastern Canada Dairy Herd Improvement. Foot lesions were classified into 6 categories: infectious, white line disease, heel erosion, ulcers, hemorrhages, and any type of foot lesions. Prevalence of each outcome was quantified using the marginal predicted mean probability estimated from a null generalized linear mixed model with a logit link, and accounted for clustering of observations by cow and by herd. Variance was partitioned to assess the variation in the probability of the outcomes attributable to each level of the data structure (day of exam, cow, and herd). Prevalence of a given foot lesion as function of milking system and of various explanatory variables (mean herd size, herd average daily production, breed of the cow, age of the cow at trimming, and year of the visit) was then estimated using a generalized linear mixed model. At least 1 foot lesion was observed in $29 \%$ of cows examined during regular trimming sessions in Québec from 2015
\end{abstract}

Received January 12, 2020.

Accepted August 4, 2020.

*Corresponding author: simon.dufour@umontreal.ca to 2018. Prevalence for any type of lesion was $27 \%$ for pipeline, $38 \%$ for robotic milking, and $41 \%$ for milking parlors. The highest prevalence of infectious lesions (mainly digital dermatitis) was observed in milking parlors and robotic systems, while the most prevalent lesions in pipeline were hemorrhages. Herd-level factors explained most of the disease probability for infectious diseases, heel erosion, and hemorrhages. Therefore, control of these diseases should be based on applying best herd-management practices. On the other hand, probabilities of white line disease and sole ulcers were mainly determined by cow-level characteristics.

Key words: dairy cattle, foot lesion, prevalence, hooftrimming

\section{INTRODUCTION}

Lameness and mastitis are probably the costliest diseases in dairies worldwide (Liang et al., 2017). Lameness costs come, in part, from treatment, but many foot lesions will also lead to a sustained reduction in milk yield (using locomotion scores: Archer et al., 2010; or lesions: Charfeddine and Pérez-Cabal, 2017), premature culling, or effects on reproductive performance (Barkema et al., 1994; Cha et al., 2010). Lameness is a clinical sign associated with pain and discomfort and is considered an indicator of an underlying problem (Flower and Weary, 2009). In addition to the substantial costs for dairy producers, lameness is widely recognized as one of the most serious welfare issues for dairy cattle (von Keyserlingk et al., 2009; Whay and Shearer, 2017). Pain and discomfort from lameness are more likely to get attention from the general public than mastitis or reproduction problems.

Between 80 and $90 \%$ of the causes of lameness in cattle are located in the area of the hoof (Cramer et al., 2008; Becker et al., 2014a; Solano et al., 2016), and foot lesions occur most frequently in the first 3 to 5 mo postpartum (Green et al., 2002). In North American dairy herds, the main foot lesions found are digital dermatitis (DD), sole ulcer, white line disease, foot rot, 
toe ulcer, and thin sole (Bicalho et al., 2009; Sanders et al., 2009; DeFrain et al., 2013). Two previous studies reported prevalence of foot lesions in dairy cattle in Canada (Cramer et al., 2008; Solano et al., 2016). Solano et al. (2016) included data from regular trimming sessions (the whole herd was trimmed at once) performed on 69 farms in Alberta. The authors used a cross-sectional study design with only 1 trimming evaluation retained for each cow. In this study, DD was the most common lesion among all housing types (present in $15 \%$ of cows and $94 \%$ of herds), followed by white line disease (5.7\% of cows) and toe ulcer $(2.6 \%$ of cows). In Solano et al. (2016), only 1 tiestall herd was included. Therefore, it is difficult to extrapolate their results to the Canadian conditions because in Canada, tiestall is the predominant barn configuration $(74 \%$ of dairy herds; Canadian Dairy Information Center, 2018). On the other hand, Cramer et al. (2008) reported results from hoof trimming sessions performed on cows originating from 150 herds (38 freestall and 142 tiestall) in Ontario, but more than 10 yr ago. The prevalence of cows having at least 1 foot lesion was higher in freestall (47\%) compared with tiestall (26\%) herds. These differences in lesion prevalence as a function of housing type highlight the importance of herd management practices as a risk factor for development of given foot lesions. However, characteristics of the cow (e.g., genetic, conformation, breed) and variation in characteristics from one day to another (e.g., DIM, age) are also important determinants of these diseases.

In 2015, as part of a larger Canadian study, a group of hoof trimmers in Québec, Canada were trained to make standardized assessments of foot lesions and to record these using a computerized recording system (Christen and Desrochers, 2015). Since 2015, electronic data from all herds evaluated by this group of hoof trimmers were collected, centralized at the Eastern Canadian DHI (Lactanet Inc., Ste-Anne-de-Bellevue, QC, Canada), and matched with other DHI cow-level data. In this database, herds were classified as a function of the milking systems used as follows: (1) pipeline milking systems, which are mostly herds housed in tiestalls, (2) milking parlors, which are mostly herds housed in freestalls, but also, to a lesser extent in bedded-packed barns, and (3) robotic milking systems, mostly herds using freestall housing. Our primary objective was to estimate the prevalence of foot lesions in dairy cows examined during regular trimming sessions performed over 4 yr (2015-2018) in Québec dairy herds and by type of milking system used (pipeline, milking parlor, or robot). A secondary objective was to describe the effect of day-to-day variation, cow, and herd characteristics on the probability of observing a given foot lesion.

\section{MATERIALS AND METHODS}

\section{Data Collection}

Hoof Trimmers Training. Initially, in December 2014, a group of 24 hoof trimmers participated in a 3-d training aimed to standardize the trimming techniques and the identification of foot lesions. A French translation of the Lesion Severity Scoring Guide (The Alberta Dairy Hoof Health Project, 2014) was used to standardize the identification and the severity of lesions. The training focused on the lesions recorded by the computerized recording system (Hoof Supervisor, Dresser, WI) including the following: DD; interdigital dermatitis; foot rot; white line disease and white line hemorrhage; heel erosion; toe ulcer; sole ulcer; sole hemorrhage; vertical, horizontal, and axial fissures; thin sole; interdigital hyperplasia; and corkscrew hooves. Lesions were recorded at the hoof level and zone of the hoof where the lesion was observed (Shearer et al., 2004). Hoof trimmers attended annual training sessions on lesion identification to ensure consistency of foot-lesions recording throughout the years. Data for the present study originated from hoof-trimming sessions performed by 17 (of the 24) trained hoof trimmers between March 23, 2015, and July 10, 2018.

Computerized Lesion Recording System. An additional 2-d training session was performed in June of 2015 to teach hoof trimmers how to use a computerized lesion-recording system (Hoof Supervisor System) to record foot lesions. The training started with an overview on lesion identification, followed by a training on how to use the online interface to download the herd DHI list of cows for trimming. Once the trimming was completed, hoof trimmers were shown how to send back the foot health information to the centralized DHI database (still using the interface and an internet connection). Matching of information of individual cow was done using permanent cow identification, birth date, and internal DHI control number. All trimming sessions conducted by these hoof trimmers since March 2015 were centralized at the Eastern Canada DHI.

\section{Sampling Frame}

Source Population. The initial database included a total of 115,828 observations performed in 53,368 animals (heifers and cows) from 609 herds between March 23, 2015, and July 10, 2018 (Figure 1). These observations corresponded to regular (e.g., preventive trims) and diagnostic or curative hoof trims (e.g., lame cows specifically presented to the hoof trimmer). Observations from therapeutic actions (e.g., bandages and 


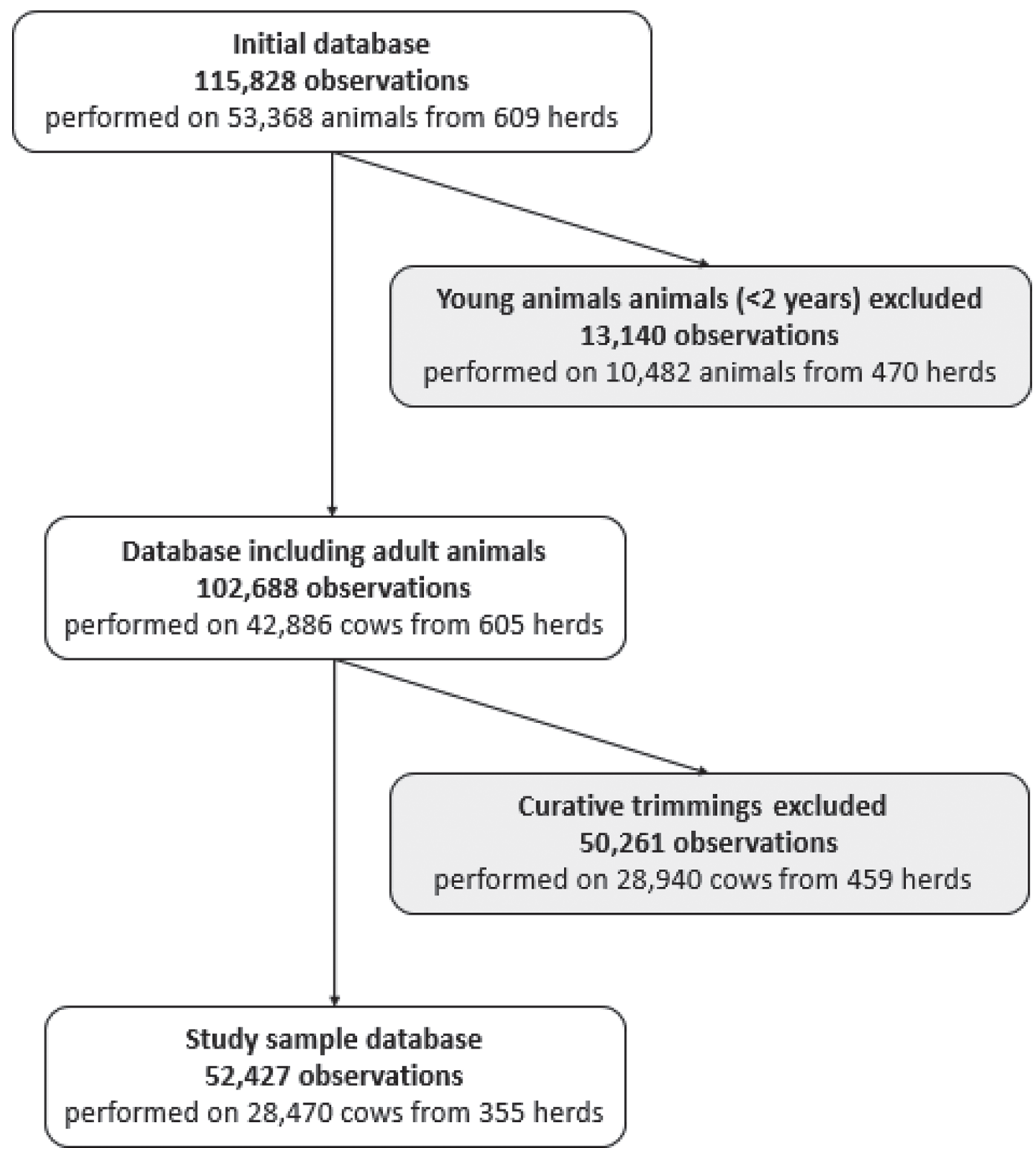

Figure 1. Number of observations in the initial database, excluded observations, and study sample analyzed to estimate the prevalence of foot lesions in dairy cows examined during regular trimming sessions performed over 4 yr (2015-2018) in Québec dairy herds. Sessions were defined as all the visits performed by the hoof trimmer in the same herd within a period of $30 \mathrm{~d}$. Of the 28,940 cows on which curative trimmings were performed, 10,513 were trimmed at different time points during a curative trimming (observation excluded) and a preventive trimming $(\geq 90 \%$ of the lactating herd was trimmed in the same session; observation included), and 18,435 were trimmed only in curative trimming sessions ( $<90 \%$ of the lactating herd was trimmed in the same trimming session; observation and animal excluded).

treatments) or follow-ups from previously diagnosed lesions (e.g., rechecks) were already excluded in the initial database $(27,140$ observations performed in 11,330 animals from 543 herds).

Study Population and Study Sample. Age at calving was not available in the database obtained from DHI. Therefore, the age of the cow at trimming was used to exclude trims performed on animals $<2$ yr old (hypothesized to be nonlactating youngstock; 13,140 observations performed on 10,482 young animals from 470 herds), provided that mean age at first calving in Québec is >24 mo (Lacroix et. al, 2014). A hoof-trimming session was defined as all the visits performed by the hoof trimmer in the same herd within a period of 30 d. The proportion of milking cows in a herd evaluated by the hoof trimmer during such a hoof-trimming session was computed for each session. Provided that the main objective of the study was to quantify the preva- 
lence of foot lesions, the study sample included only trimming sessions in which $\geq 90 \%$ of the lactating herd was trimmed (i.e., a regular preventive trimming session as compared with sessions where a limited number of, possibly lame, animals will be presented to the hoof trimmer). To avoid an overestimation of the prevalence, trimming sessions in which a smaller proportion of the herd was trimmed (possibly all lame cows plus a fraction of the healthy cows) were not considered.

\section{Foot Lesions}

Foot lesions recorded at foot-level during a given trimming session were collapsed at the cow level to report presence or absence of a given lesion on a given animal at a given trimming session. Foot lesions were further grouped into 6 categories: (1) infectious (including DD and interdigital dermatitis), (2) white line disease, (3) heel erosion, (4) ulcers (including toe and sole ulcer), (5) hemorrhages (including sole and white line hemorrhage), and (6) any type of foot lesions (i.e., any of the preceding lesions).

\section{Statistical Analyses}

Analyses were conducted in Stata statistical software (release 15; Stata Corp. LP, College Station, TX), and SAS statistical software (version 9.2; SAS Institute, Cary, NC). Initially, a description of the study sample and the hoof-trimming visits (frequency and percentage of the herd trimmed) was calculated, followed by the quantification of the mean herd prevalence of foot lesions by year and by milking system. Six outcome variables were explored that corresponded to the following categories of foot lesions: infectious lesions, white line disease, heel erosion, ulcers, hemorrhages, and any type of foot lesion.

Estimating Prevalence of Foot Lesions and Effect of Day, Cow, and Herd-level Characteristics. The prevalence of each outcome was quantified using the marginal predicted mean probability estimated from a null (i.e., a model without fixed predictors) generalized linear mixed model (GLMM) with a logit link, and accounted for clustering of observations by cow and by herd. The model was as follows:

$$
\operatorname{Logit}\left(p_{i j k}\right)=\beta_{0}+v_{h e r d(k)}+u_{\operatorname{cow}(j k)},
$$

where $p_{i j k}$ is the probability of the outcome for the $i$ th observation (i.e., the observation made on a given trimming session on a given cow) of the $j$ th cow from the $k$ th herd; $\beta_{0}$ is the intercept; $v_{h e r d(k)}$ is the herd random effect, normally distributed with mean of 0 and variance $\sigma_{h}^{2}$; and $u_{\text {cow }(j k)}$ is the cow random effect with mean of 0 and variance $\sigma_{c}^{2}$. The variance obtained from this null GLMM was then partitioned to assess the variation in the probability of the outcomes attributable to each of the data levels (herd, cow, and trimming session), using the simulation method described by Goldstein et al. (2002).

Explanatory Variables. Explanatory variables at the herd level included type of milking system (pipeline, milking parlor, and robot), mean herd size (in number of milking cows), and herd average daily production (measured in each herd in each year in $\mathrm{kg} /$ cow per day). The only explanatory variable at the cow level was the breed of the cows (Holstein vs. other breeds). At the observation level, explanatory variables included the age of the cow at trimming and the year of the visit (2015, 2016, 2017, or 2018).

A simple GLMM with a logit link was used to evaluate the unconditional associations between each explanatory variable and each outcome. Potential explanatory variables (other than type of milking system) to be included in the multivariable GLMM were selected based on their $P$-values in the univariable model (using an $\alpha$ $<0.2$ ) as proposed previously (Dohoo et al., 1997). The assumption of linearity of continuous explanatory variables (mean herd size, herd average daily production, and age of the cow) with the log odds of each outcome was assessed graphically. Herd size was kept continuous for the outcomes "ulcers" and "hemorrhages" (provided that the assumption of linearity was respected) and scaled to represent the change for every 25 -cow increase in herd size. For the remaining outcomes (any type of foot lesion, infectious, white line disease, and heel erosion), herd size was used as dichotomous variable using the mean as the cut-off ( $\leq 65$ cows and $>65$ cows). Herd average daily production was kept continuous for the outcomes "white line disease," "heel erosion," and "hemorrhages." For the remaining outcomes (any type of foot lesion, infectious, and ulcers), herd average daily production was used as a dichotomous variable using the mean as the cut-off $(\leq 27 \mathrm{~kg} / \mathrm{cow}$ per day and $>27$ $\mathrm{kg} /$ cow per day). The explanatory variable age of the cow was kept categorical for all the outcomes $(2,3$, and $\geq 4$ yr). Prior to multivariable analyses, we investigated the correlation between explanatory variables using Spearman's rank correlation coefficient (correlation if $\rho \geq 0.5)$, simple linear regression $\left(\mathrm{R}^{2}>0.5\right)$, and simple logistic regression (odds ratio; $\mathbf{O R}>8$ and $P$ $<0.05$ ), depending on the nature of the variable (e.g., continuous or categorical). No correlation was observed between the explanatory variables. 
Effect of Explanatory Variables on Prevalence of Foot Lesions. To assess the prevalence of foot lesions among milking systems, the following GLMM was used with each outcome:

$$
\operatorname{Logit}\left(p_{i j k}\right)=\beta_{0}+\beta_{1} x_{i j k}+v_{h e r d(k)}+u_{\operatorname{cow}(j k)},
$$

where $p_{i j k}$ is the probability of the outcome for trimming session $i$ of cow $j$ from herd $k ; x_{i j k}$ is a vector of values for explanatory variables for that observation; $\beta_{0}$ is the intercept; $\beta_{1}$ is a vector of regression coefficients for the explanatory variables; $v_{\text {herd }(k)}$ is the herd random effect; and $u_{\operatorname{cow}(j k)}$ is the cow random effect, both assumed to have mean of zero with variances of $\sigma_{h}^{2}$ and $\sigma_{c}^{2}$, respectively. Then, the interaction between explanatory variables from the univariable analysis with $P<0.2$ (1 at the time) and the variable milking system was assessed by adding an interaction term between them. Interaction terms were only retained if $P<0.05$. The predicted probability of the outcome was estimated for each model using the margins command in Stata. Whenever an interaction between type of milking system and a given explanatory variable was observed $(P$ $<0.05$ ), results were then presented as proposed by Knol et VanderWeele (2012) or graphically. Normality of residuals and their homoscedasticity at the highest level (herd) were assessed graphically using Q-Q plots and plots of residuals against the predicted values.

\section{RESULTS}

\section{Hoof-Trimming Sessions}

The number of hoof-trimming sessions performed per herd per year for the different type of trimming sessions $(<90 \%$ of the lactating herd was trimmed: curative trimming session; $\geq 90 \%$ of the lactating herd was trimmed: preventive trimming session) are presented in Table 1. Over the duration of the study, curative trimming sessions were more frequent than preventive trimming sessions. The modal number of preventive trimming sessions per year was 2, but numerous herds used only 1 preventive trimming session per year, and a few herds used 4 to 6 preventive trimming sessions per year. The distribution of typical trimming sessions performed on adult cows in Québec dairy herds between 2015 and 2018 as a function of the proportion of the adult herd trimmed per session are presented in Figure 2. Hereafter, only the results from trimming sessions in which $\geq 90 \%$ of the lactating herd was trimmed (e.g., preventive trimming sessions) will be presented.

\section{Study Sample}

The study sample included 52,427 observations (45.3\% of the initial observations; observation on a cow during a specific trimming session) performed on 28,470 cows from 355 herds (Figure 1). Among these herds, a pipeline was the most common milking system $(\mathrm{n}=301)$, followed by robot $(\mathrm{n}=34)$, and milking parlor $(\mathrm{n}=18)$. Milking system was not available for 2 herds. Herd average milk daily production (in $\mathrm{kg} /$ cow per day) varied from $13.2 \mathrm{~kg}$ to $36.4 \mathrm{~kg}$ (mean = $27.2 \mathrm{~kg}$; median $=27.6 \mathrm{~kg}$ ). Herd size varied from 7 to 280 cows $($ mean $=65$ cows; median $=59$ cows $)$. Most of the cows were Holstein ( $\mathrm{n}=27,247$ cows); however, other breeds were also represented (Jersey: $\mathrm{n}=735$; Ayrshire: $\mathrm{n}=358$; other breeds: $\mathrm{n}=130)$. Age of cows varied from 2 to $16 \mathrm{yr}($ average $=4.2 ;$ median $=3.7)$.

\section{Mean Herd Prevalence of Foot Lesions by Type of Milking System}

At the herd level, a general reduction in the predicted mean herd prevalence of lesions (for most outcomes) during the study period was observed. However, performing a comparison of the mean herd prevalence by year was difficult using these data, provided that not all of the months are represented for the first (2015) and the last year (2018) of the study period (and given that some types of foot lesions may have a seasonal component). The predicted mean herd prevalence of lesions by year is presented in Table 2 . When analyzing the distribution of mean herd prevalence by year and by milking system (Figure 3), median herd prevalence of infectious foot diseases was lower for pipeline compared with milking parlor and robot (Figure 3B). For hemorrhages, median herd prevalence was lower for milking parlor compared with pipeline and robot (Figure 3F).

\section{Cow-Level Prevalence of Foot Lesions by Type of Milking System}

A total of 11,229 cows $(39.4 \%)$ had at least 1 lesion during the study period, and 3,976 (14\%) had multiple lesions. When accounting for clustering at the cow and herd levels, the prevalence of foot lesions (any type of foot lesion) was estimated at $28.9 \%$ (95\% CI: $27.2-30.7$; Table 3$)$. The prevalence of any type of lesion was lower for pipeline (27.2; 95\% CI: 25.4-29.1) than robot (37.7; 95\% CI: 31.5-43.8) and milking parlor (40.5; 95\% CI: 31.7-49.3). Hemorrhages had the highest prevalence (10.6\%; 95\% CI: 9.4-11.8), followed by ulcers $(8.9 \%$; 95\% CI: 8.3-9.5), infectious lesions (8.4\%; $95 \%$ CI: 
7.1-9.7), heel erosion (7.6\%; 95\% CI: 6.4-8.8), and white line disease $(2.3 \%$; $95 \%$ CI: $1.9-2.6)$.

Effect of Trimming Session, Cow, and Herd Characteristics on Probability of Foot Lesions. Proportion of foot lesions explained by trimming session, cow, and herd characteristics are presented in Table 3. Herd-level characteristics explained the largest proportion of infectious foot diseases (0.67), heel erosion (0.71), and hemorrhages (0.64) compared with cow and trimming-session characteristics. On the other hand, white line disease and ulcers were explained mainly by cow-level characteristics (0.59 and 0.77 respectively; Table 3).

Effect of Explanatory Variables on Prevalence of Foot Lesions. Results from univariable analyses between explanatory variables and each outcome are presented in Supplemental Table S1 (https://doi.org/ 10.3168/jds.2020-18191).

Age. An interaction was observed between age and type of milking system for the outcomes "any type of foot lesion" and "infectious." In general, the prevalence of cows with any type of foot lesion or with an infectious lesion were higher for cows milked in milking parlors or robotic milking systems (mainly loose housing sys- tems) compared with pipeline milking systems (mainly tiestall housing systems), regardless of the cow's age (Table 4). The marginal predicted mean probability of any type of foot lesion as a function of age and milking system is presented in Figure 4A. The predicted prevalence of any type of foot lesion increased with age, regardless of the milking system. The marginal predicted mean probability of infectious foot lesions by milking system and age of the cows is presented in Figure 4B. Briefly, for cows milked in a pipeline milking system, prevalence of infectious foot lesions increased with age. In cows milked in a milking parlor, however, predicted prevalence of infectious foot lesions decreased with age. Finally, for cows milked using robotic milkers, prevalence of infectious foot lesions did not appear to be influenced by the cow's age. An interaction between age and milking system could not be demonstrated for the remaining outcomes (white line disease, heel erosion, ulcers, and hemorrhages). For all of these foot lesions, odds of lesions increased with the age of the cow (Table 4).

Breed. An interaction between breed and milking system could not be confirmed in any of the outcomes (any type of foot lesion, infectious, white line disease,

Table 1. Number of trimming sessions performed per herd per year

\begin{tabular}{|c|c|c|c|c|c|c|}
\hline \multirow{2}{*}{$\begin{array}{l}\text { Type of hoof-trimming } \\
\text { session }\end{array}$} & \multirow{2}{*}{$\begin{array}{l}\text { Number of hoof-trimming } \\
\text { sessions per year }\end{array}$} & \multicolumn{4}{|c|}{ Number of herds per year } & \multirow[b]{2}{*}{ Total } \\
\hline & & $2015^{1}$ & 2016 & 2017 & $2018^{1}$ & \\
\hline \multirow[t]{5}{*}{ All trimming sessions } & 1 & 145 & 199 & 207 & 211 & 762 \\
\hline & 3 & 12 & 158 & 123 & 9 & 302 \\
\hline & 4 & 4 & 64 & 36 & 4 & 108 \\
\hline & 5 & 5 & 18 & 34 & 0 & 57 \\
\hline & 9 & 0 & 0 & 7 & 0 & 7 \\
\hline Total & & 250 & 775 & 709 & 274 & 2,008 \\
\hline \multirow[t]{4}{*}{ Curative trimming $^{2}$} & 1 & 76 & 119 & 116 & 111 & 422 \\
\hline & 2 & 49 & 158 & 138 & 41 & 386 \\
\hline & 3 & 11 & 106 & 90 & 9 & 216 \\
\hline & 4 & 4 & 54 & 30 & 4 & 92 \\
\hline Total & & 145 & 481 & 419 & 165 & 1,210 \\
\hline \multirow[t]{6}{*}{ Preventive trimming ${ }^{3}$} & 1 & 69 & 80 & 91 & 100 & 340 \\
\hline & 2 & 35 & 151 & 158 & 9 & 353 \\
\hline & 3 & 1 & 52 & 33 & 0 & 86 \\
\hline & 4 & 0 & 10 & 6 & 0 & 16 \\
\hline & 5 & 0 & 0 & 2 & 0 & 2 \\
\hline & 6 & 0 & 1 & 0 & 0 & 1 \\
\hline Total & & 105 & 294 & 290 & 109 & 798 \\
\hline
\end{tabular}

${ }^{1}$ Not all months are represented for 2015 and 2018, provided that the study was performed between March 2015 and July 2018.

${ }^{2}$ Curative trimming: $<90 \%$ of the lactating herd was trimmed in the same session. Includes sessions performed on 28,940 cows.

${ }^{3}$ Preventive trimming: $\geq 90 \%$ of the lactating herd was trimmed in the same session. Includes sessions performed on 28,470 cows. 




Figure 2. Proportion of adult lactating cows ( $\geq 2$ yr) trimmed per hoof-trimming session performed in 609 Québec dairy herds between March 2015 and July 2018.

heel erosion, ulcers, and hemorrhages). The odds of all of the outcomes except white line disease were lower for cows from other breeds compared with Holstein cows (Table 5).

Average Daily Milk Production. An interaction was observed between herd average daily production and milking system for infectious lesions (Table 6 and Figure 5), white line disease, and hemorrhages (Figure 6 ). We could not demonstrate an association between odds of infectious foot lesions and the herd average daily production in cows milked in herds using a pipeline or robotic milking system (Table 6 and Figure 5). However, odds of infectious lesions were higher in cows from herds using milking parlors when average daily production was $\leq 27 \mathrm{~kg} /$ cow per day (Table 6 ).

Regarding white line disease, the predicted prevalence of lesions increased as a function of herd milk production in cows milked using milking parlors and robotic milking, but decreased as a function of herd milk production in cows from herds milked with a pipeline system (Figure 6A). For hemorrhages, the predicted prevalence of lesions increased as a function of herd milk production only for cows milked in a milking parlor (Figure 6B). We could not demonstrate variation of the predicted prevalence of hemorrhages as a function of herd milk production for cows milked in pipeline

Table 2. Predicted mean herd prevalence ${ }^{1}$ of foot lesions by year in Québec dairy herds from March 2015 to July 2018

\begin{tabular}{|c|c|c|c|c|}
\hline Category of foot lesion & \multicolumn{4}{|c|}{ Mean herd prevalence ( $95 \% \mathrm{CI}$ ) by year } \\
\hline Any type of foot lesion & $45.1(40.9-49.3)$ & $41.7(38.6-44.9)$ & $30.6(27.7-33.5)$ & $17.6(14.1-21.0)$ \\
\hline White line disease & $3.8(2.9-4.8)$ & $4.6(3.6-5.5)$ & $2.1(1.6-2.7)$ & $0.8(0.3-1.3)$ \\
\hline Heel erosion & $12.2(9.0-15.4)$ & $11.6(9.5-13.8)$ & $8.6(7.0-10.3)$ & $4.6(2.8-6.5)$ \\
\hline Ulcers & $17.7(15.1-20.3)$ & $15.4(13.8-17.0)$ & $9.1(7.9-10.2)$ & $3.1(2.0-4.2)$ \\
\hline
\end{tabular}

${ }^{1}$ Predictions made using a generalized linear mixed model, with cow and herd random intercepts and using a logit function. 

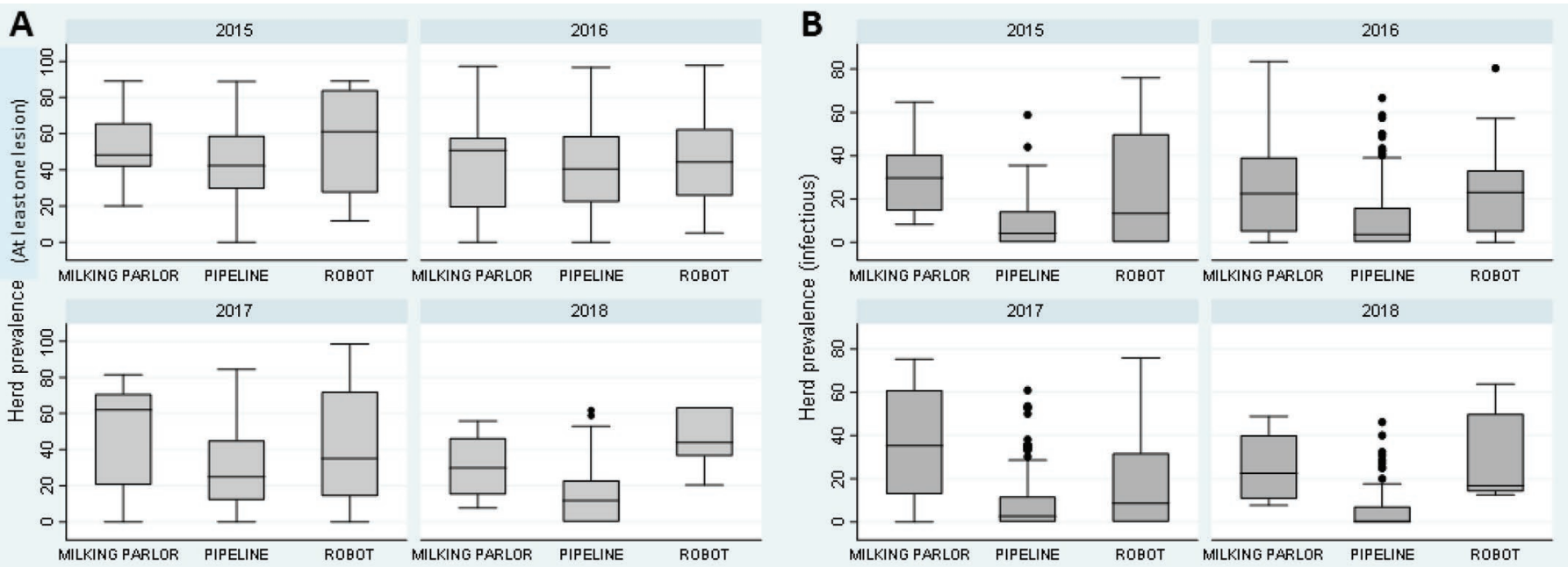

C
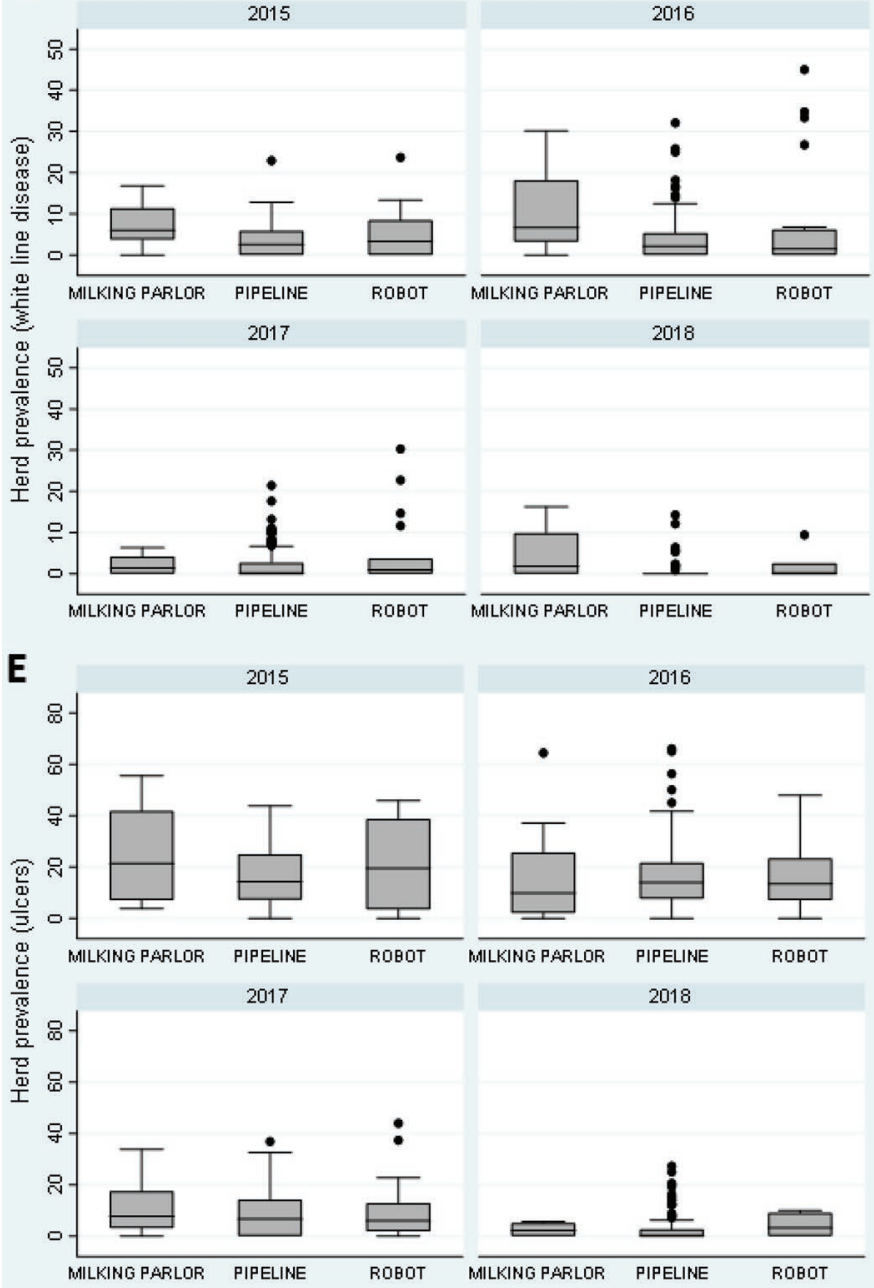

D
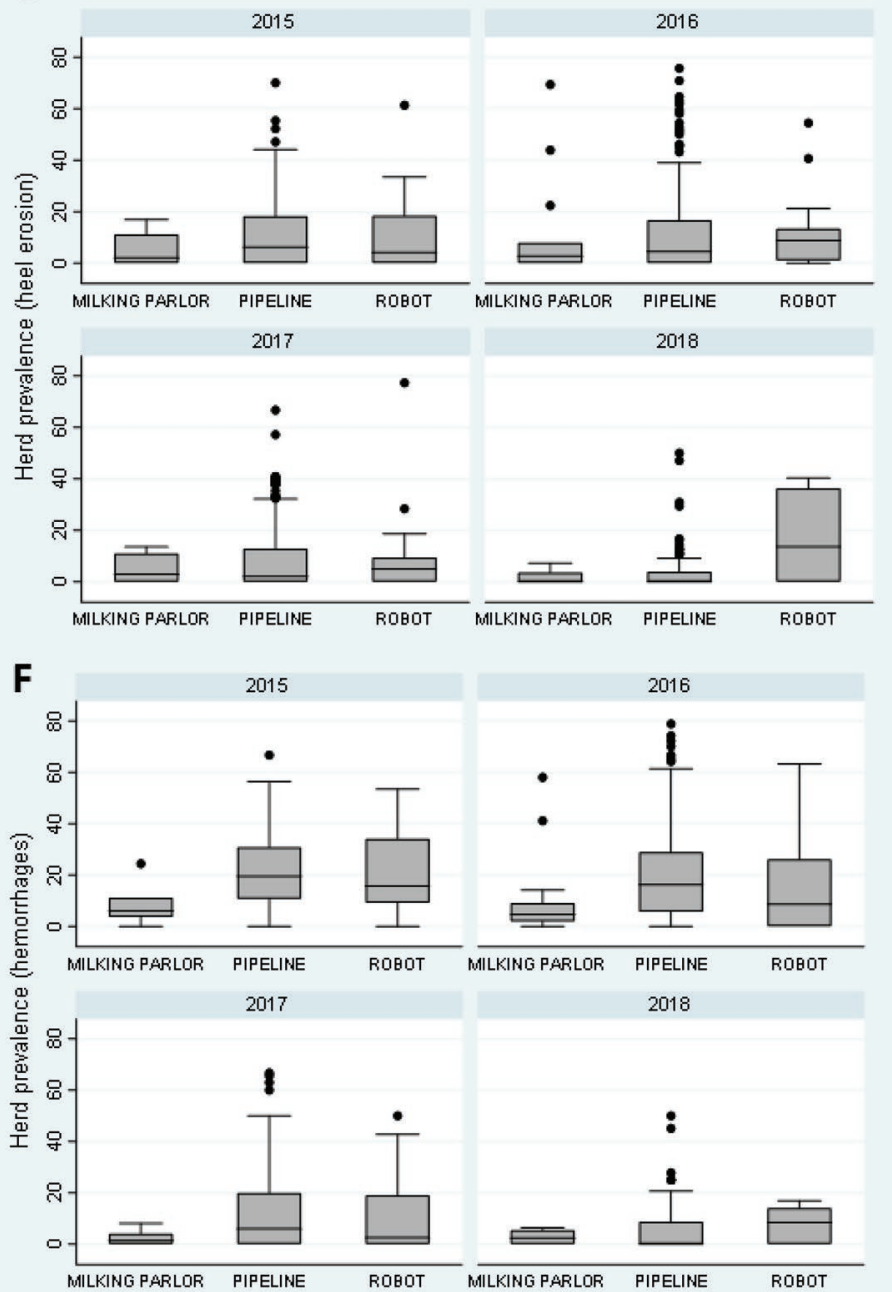

Figure 3. Herd prevalence of foot lesions by year and type of milking system for (A) any type of foot lesion, (B) infectious lesions, (C) white line disease, (D) heel erosion, (E) ulcers, and (F) hemorrhages. Boxplots display the distribution of mean herd prevalence. The lower and upper edges of the boxes represent the first and third quartiles, respectively; the midlines represent the median; and the whiskers represent the minimum and maximum values after excluding the outliers (dots). 
Arango-Sabogal et al.: PREVALENCE OF FOOT LESIONS IN QUÉBEC DAIRIES
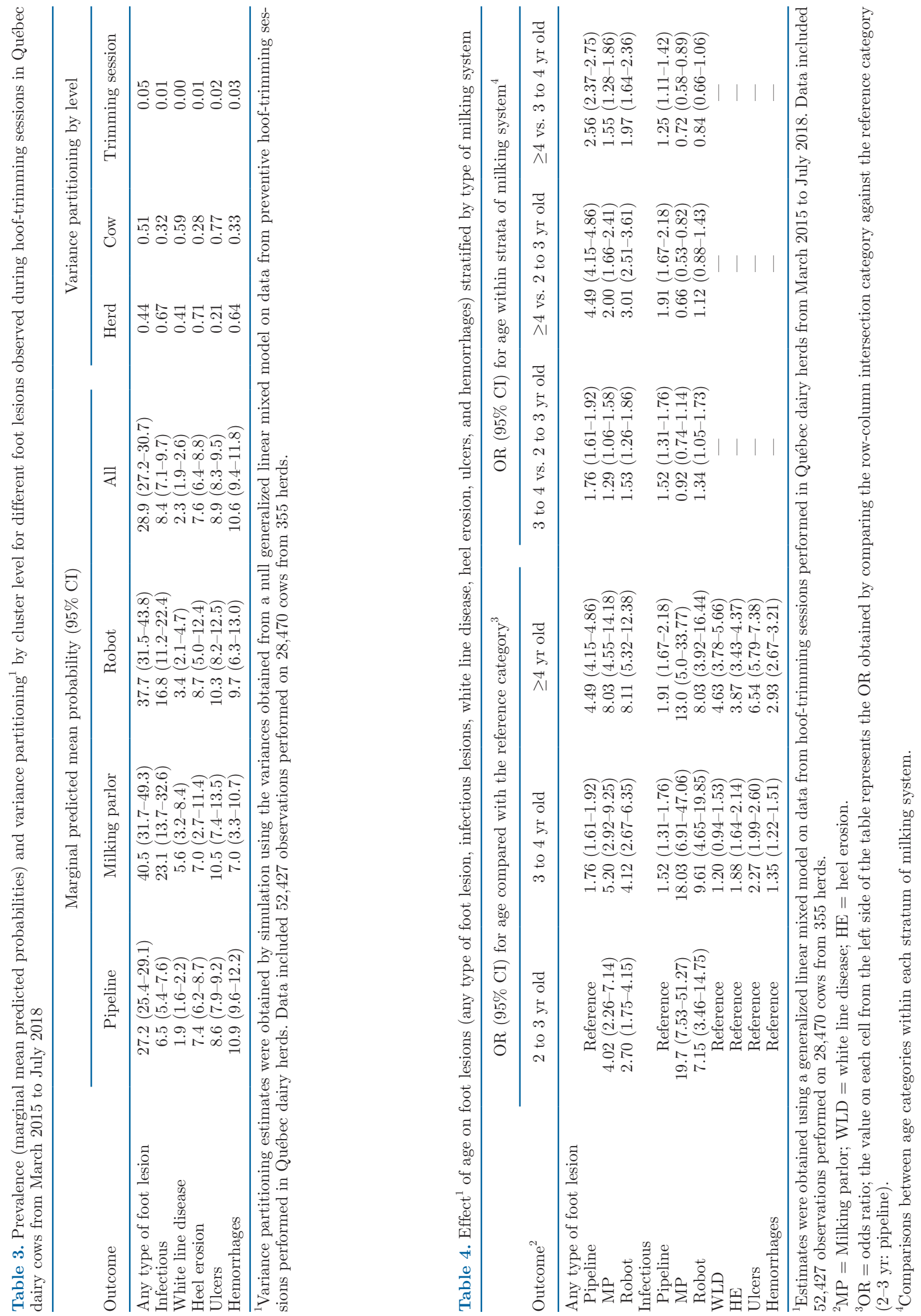
or robotic milking systems (Figure $6 \mathrm{~B}$ ). We could not demonstrate an association between prevalence of heel erosion, ulcers, or any type of foot lesion and the herd milk production level (Supplemental Table S1, https:// doi.org/10.3168/jds.2020-18191).

Herd Size. An interaction between herd size and type of milking system could not be established for any of the outcomes (infectious, heel erosion, and hemorrhages). The odds of infectious diseases and heel erosions were higher for cows originating from a herd with


Figure 4. Predicted prevalence (marginal predicted mean probabilities) and $95 \%$ confidence intervals of (A) any type of foot lesion and (B) infectious foot lesions by milking system and age of the cows. Estimates were obtained using a generalized linear mixed model on data from hoof-trimming sessions performed in Québec dairy herds from March 2015 to July 2018. Data included 52,427 observations performed on 28,470 cows from 355 herds.
$>65$ cows compared with cows from herds with $\leq 65$ cows (Table 7). The odds of hemorrhages decreased by $1 \%$ for every 25 -cow increase in herd size $(\mathrm{OR}=0.99$; 95\% CI: 0.98-0.99; Figure 7). We could not highlight an association between prevalence of ulcers, white line disease, or at least one type of lesion and herd size (Supplemental Table S1).

Year of the Visit. An interaction between year of the visit and type of milking system was observed for the outcome heel erosion (Table 8). The marginal predicted mean probability of heel erosion by milking system and year of the visit is presented in Figure 8. Briefly, in cows milked using pipeline milking systems, prevalence of heel erosion lesions slightly increased from March 2015 to July 2018. In cows milked using milking parlor or robotic milking systems, prevalence of heel erosion lesions varied by year, but with no particular striking pattern. An association between year of the visit and milking system was not observed for the outcome ulcers (Table 8). The odds of ulcers were lower in 2016 (OR $=0.87 ; 95 \%$ CI: $0.76-0.99)$ and $2018(\mathrm{OR}=0.72 ; 95 \%$ CI: 0.59-0.87) compared with 2015.

\section{DISCUSSION}

\section{Prevalence of Foot Lesions}

The prevalence of foot lesions in dairy cows examined during regular trimming sessions performed over $4 \mathrm{yr}$ in Québec dairy herds was estimated. About 29\% of the cows examined during regular trimming sessions presented at least 1 foot lesion. It is important to highlight, though, that clinical relevance (e.g., lameness, milk yield reduction) of these lesions was not evaluated at this stage. Trimmers were simply instructed to record all lesions. Thus, we cannot comment, for instance,

Table 5. Effect of breed on foot lesions (any type of foot lesion, infectious lesions, white line disease, heel erosion, ulcers, and hemorrhages)

\begin{tabular}{llc}
\hline & \multicolumn{2}{c}{ Breed } \\
\cline { 2 - 3 } Outcome & Holstein & Other \\
\hline Any type of foot lesion & Reference & $0.26(0.20-0.34)$ \\
Infectious & Reference & $0.26(0.16-0.41)$ \\
White line disease & Reference & $0.66(0.40-1.10)$ \\
Heel erosion & Reference & $0.21(0.12-0.37)$ \\
Ulcers & Reference & $0.53(0.38-0.74)$ \\
Hemorrhages & Reference & $0.31(0.20-0.47)$ \\
\hline
\end{tabular}

${ }^{1}$ Estimates were obtained using a generalized linear mixed model on data from hoof-trimming sessions performed in Québec dairy herds from March 2015 to July 2018. Data included 52,427 observations performed on 28,470 cows from 355 herds. 

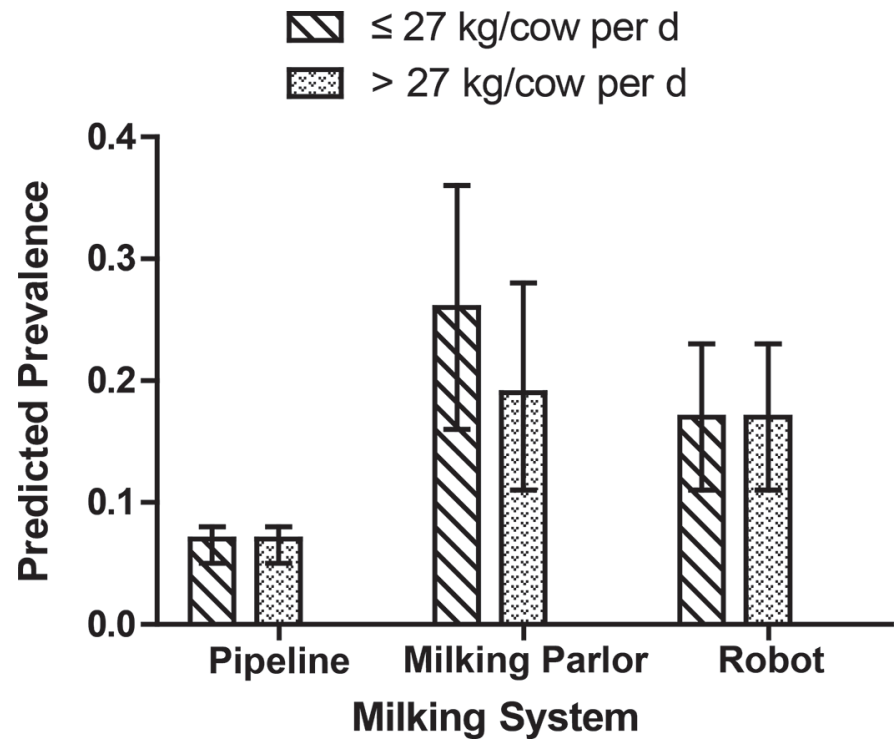

Figure 5. Predicted prevalence (marginal predicted mean probabilities) and $95 \%$ confidence intervals of infectious diseases by milking system and herd average daily production ( $\mathrm{kg} / \mathrm{cow}$ per day). Estimates were obtained using a generalized linear mixed model on data from hoof-trimming sessions performed in Québec dairy herds from March 2015 to July 2018. Data included 52,427 observations performed on 28,470 cows from 355 herds.

on the relevance of lesions such as sole hemorrhages. To the best of our knowledge, this is the first study conducted in North America analyzing such a large database $(>50,000$ observations performed on $>28,000$ cows from 355 herds) that included trimming sessions where almost the entire herd was trimmed $(\geq 90 \%)$.

In the present study, milking system was used as a proxy to evaluate barn configuration where pipeline corresponded to tiestall, and milking parlor and robotic system to freestall configurations. Our prevalence estimates for at least 1 foot lesion for cows milked in pipeline systems and milking parlors are similar to those reported by Cramer et al. (2008) for tiestall and freestall barns, respectively ( $27 \%$ vs. $26 \%$ and $41 \%$ vs. $47 \%$ ). In Ontario, tiestall herds are also predominant, although in a lesser extent than Québec (68\% vs. $92 \%$ of the herds) (Canadian Dairy Information Center, 2018). In the present study, the prevalence of foot lesions for cows milked using robotic milking systems (38\%) was similar to that observed for cows milked in milking parlors. This finding is somehow expected given that both milking systems correspond mainly to loose housing systems. On the other hand, in parlor milking systems, cows will usually be assembled before each milking and will have to wait for a certain period of time with little opportunity for lying down. This is not the case in robotic milking herds and could explain, in part, differences in foot lesions between these 2 latter groups. Similar to other previous studies (Somers et al., 2003; Holzhauer et al., 2006; Cramer et al., 2008), the highest prevalence was observed for infectious diseases in loose housing systems (milking parlors and robotic systems) in our study. However, unlike Cramer's study, hemorrhages were the most common among pipeline systems, while infectious diseases ranked in the fourth place. Even if tiestalls predominate in Ontario and Québec, our results indicate that there might be dissimilarities between the 2 provinces or between study periods (e.g., herd management practices) that contribute to the marked differences in infectious foot disease prevalence ( $16 \%$ vs. $7 \%$, respectively).

One of the main advantages of the present study is that, with the statistical approach used, variance partitioning could be computed to describe how the probability of disease is affected by either day-to-day variation, foot or cow characteristics, or herd characteristics (Goldstein et al., 2002). Knowing how the probability of a lesion is influenced by factors related to these different levels of the hierarchy can help target interventions to prevent them. For instance, if the probability of a foot lesion is mainly determined by herd-level characteristics (e.g., infectious diseases, heel

Table 6. Effect ${ }^{1}$ of herd average daily production (in $\mathrm{kg} / \mathrm{cow}$ per day) on infectious foot lesions, stratified by milking system

\begin{tabular}{|c|c|c|c|}
\hline \multirow[b]{2}{*}{ Outcome } & \multicolumn{2}{|c|}{$\begin{array}{l}\text { OR }(95 \% \text { CI }) \text { for herd average daily production } \\
\text { compared with the reference category }{ }^{2}\end{array}$} & \multirow{2}{*}{$\begin{array}{l}\text { OR }(95 \% \text { CI }) \text { for herd average daily production } \\
\text { within strata of milking system }{ }^{3} \\
>27 \mathrm{~kg} / \text { cow per day vs. } \leq 27 \mathrm{~kg} / \text { cow per day }\end{array}$} \\
\hline & $\leq 27 \mathrm{~kg} / \mathrm{cow}$ per day & $>27 \mathrm{~kg} /$ cow per day & \\
\hline Pipeline & Reference & $1.00(0.80-1.26)$ & $1.00(0.80-1.26)$ \\
\hline Milking parlor & $13.11(5.02-34.20)$ & $6.92(2.63-18.20)$ & $0.53(0.41-0.68)$ \\
\hline Robot & $5.21(2.48-10.93)$ & $5.27(2.55-10.88)$ & $1.01(0.73-1.41)$ \\
\hline
\end{tabular}

${ }^{1}$ Estimates were obtained using a generalized linear mixed model on data from hoof-trimming sessions performed in Québec dairy herds from March 2015 to July 2018. Data included 52,427 observations performed on 28,470 cows from 355 herds.

${ }^{2}$ The value on each cell from the left side of the table represents the OR obtained by comparing the row-column intersection category against the reference category $(\leq 27 \mathrm{~kg} /$ cow per day: pipeline). $\mathrm{OR}=$ odds ratio.

${ }^{3}$ Comparisons between herd average daily production categories within each stratum of milking system. 


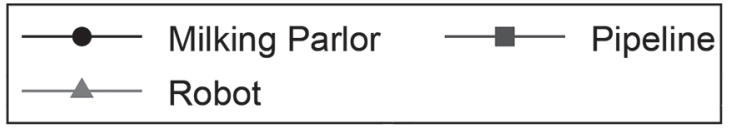

A

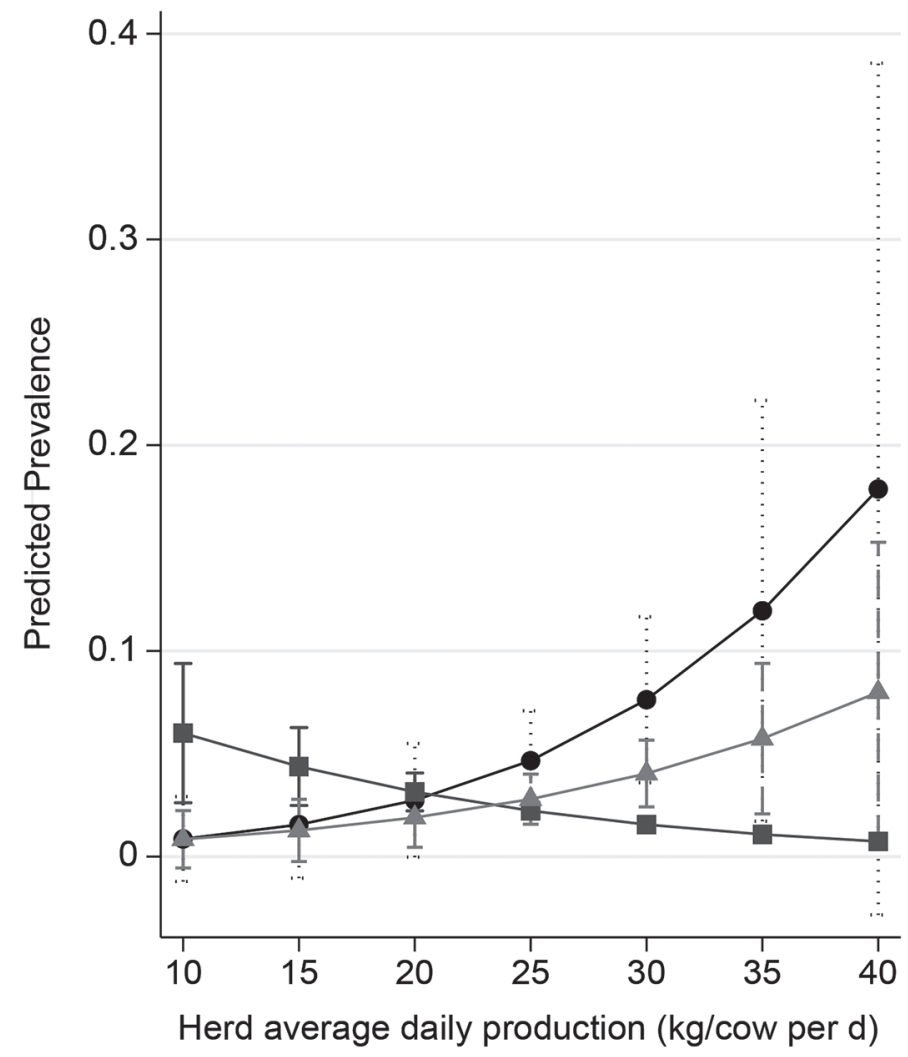

B

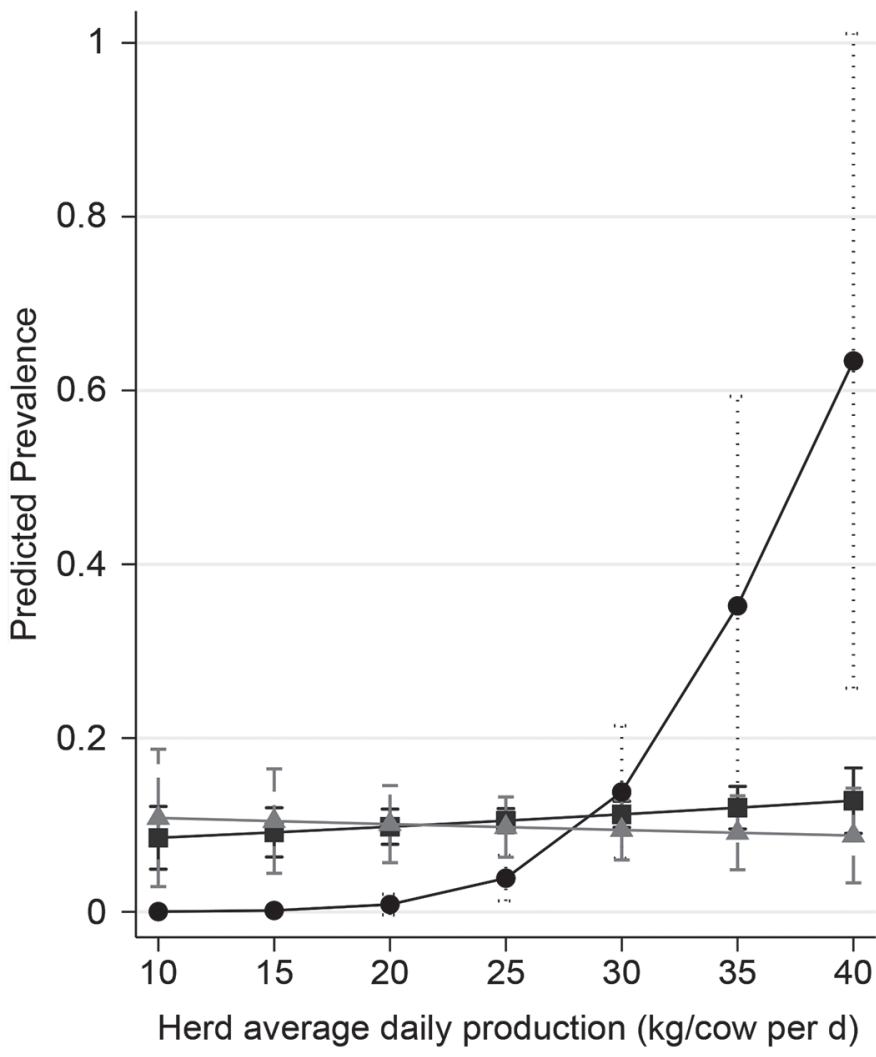

Figure 6. Predicted prevalence (marginal predicted mean probabilities) and 95\% confidence intervals of (A) white line disease and (B) hemorrhages by milking system and herd average daily production $(\mathrm{kg} / \mathrm{cow}$ per day). Estimates were obtained using a generalized linear mixed model on data from hoof-trimming sessions performed in Québec dairy herds from March 2015 to July 2018. Data included 52,427 observations performed on 28,470 cows from 355 herds.

erosion, hemorrhages), then one could hypothesize that altering herd management will have a substantial effect on disease incidence. On the other hand, if probability of a lesion is mainly determined by cow-level characteristics (e.g., white line disease, ulcers) then one could hypothesize that genetic improvement is more likely to

Table 7. Effect ${ }^{1}$ of herd size on infectious lesions and heel erosion

Herd size

(odds ratio and $95 \% \mathrm{CI}$ )

\begin{tabular}{llc}
\cline { 2 - 3 } Outcome & $\leq 65$ cows & $>65$ cows \\
\hline Infectious & Reference & $1.32(1.04-1.68)$ \\
Heel erosion & Reference & $1.51(1.22-1.87)$ \\
\hline
\end{tabular}

${ }^{1}$ Estimates were obtained using a generalized linear mixed model on data from hoof-trimming sessions performed in Québec dairy herds from March 2015 to July 2018. Data included 52,427 observations performed on 28,470 cows from 355 herds. have a substantial effect on disease incidence compared with altering herd management.

The variance partitioning analysis indicated that foot lesions were determined, to a greater extent, by herd- or cow-level characteristics and less likely by characteristics at the trimming-session level (i.e., trimming session determined $\leq 5 \%$ of any of the outcomes). Infectious diseases, heel erosion, and hemorrhages were mainly determined by herd-level characteristics $(\geq 64 \%)$. For instance, the probability of infectious diseases was at least 2 and 3 times higher for cows milked in robotic systems $(17 \%)$ and milking parlors $(23 \%)$ than for cows milked in pipelines $(7 \%)$, suggesting differences in herdlevel characteristics between tiestall and loose housing systems. Control measures to prevent infectious foot diseases include improving cleanliness and housing cows in drier environments (Berry, 2001; Borderas et al., 2004). In general, in tiestall configurations, a cow's 
environment is drier, and thus the cow's foot has a lower risk of fecal cross-contamination and interdigital trauma, which may contribute to a lower risk of infectious diseases compared with loose housing systems (milking parlors and robotic systems).

Similar to infectious diseases, one might expect to observe important differences between the prevalence of heel erosion and hemorrhages among the milking systems studied. However, this was not the case, even if variance partitioning analysis indicated an important herd-level component that determined the probability of these lesions. In this case, we hypothesize that some herd characteristics that affect the probability of these lesions might be common, irrespective of the types of barn configuration of the farms in our study (e.g., abrasiveness of the floor).

In the same way, one might expect to observe no differences among milking systems between the prevalence of diseases determined mostly by cow-level characteristics (e.g., white line disease and ulcers; $\geq 59 \%$ ). This was the case of ulcers. However, for white line disease, the prevalence for cows milked in pipeline systems was considerably lower (a third) than that for milking parlors. Variance partitioning analysis indicated that there was still $41 \%$ of the white line disease process that might be explained by herd-level characteristics. It has been suggested that mechanical stresses to the white line that are likely to occur in milking parlor holding areas (e.g., cows being pushed laterally or medially while their hooves are steadily placed on the floor) may favor the development of white line disease (Shearer and van Amstel, 2017). Prolonged standing affects the blood flow, resulting in ischemia, hypoxia, necrosis, and separation of the white line in the apex (Greenough, 2007); therefore, it is a risk factor for lameness in cows milked in milking parlors, especially when cows stand on hard surfaces (Bell et al., 2009).

\section{Effect of Milking System and Other Explanatory Variables}

The effect of cow- and herd-level predictors on foot lesion prevalence and their variation by milking system was also explored. In the present study, an interaction between any of the predictors and milking system suggested that the effect of the predictor on the prevalence of the outcomes varied depending on the housing conditions of the cows. Such interaction was observed for age of the cow (for the outcomes: any type of lesion and infectious), average herd daily production (for the outcomes: infectious, white line disease, and hemorrhages), and year of the visit (for the outcome heel erosion).

Age. As expected, we observed that the prevalence of foot lesions increased with the age of the cow. How-

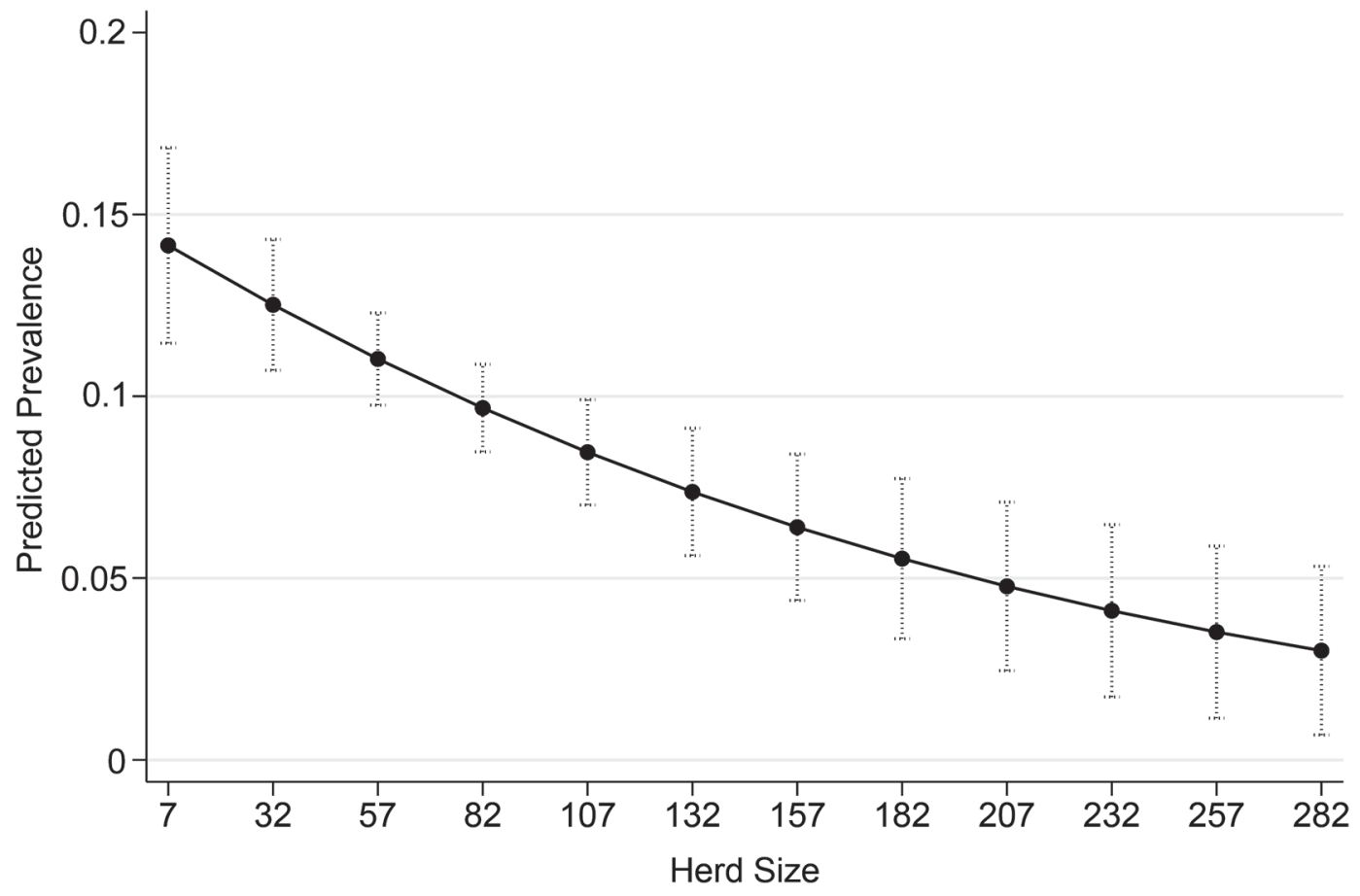

Figure 7. Predicted prevalence (marginal predicted mean probabilities) and $95 \%$ confidence intervals of hemorrhages by herd size (increase by every 25 cows). Estimates were obtained using a generalized linear mixed model on data from hoof-trimming sessions performed in Québec dairy herds from March 2015 to July 2018. Data included 52,427 observations performed on 28,470 cows from 355 herds. 


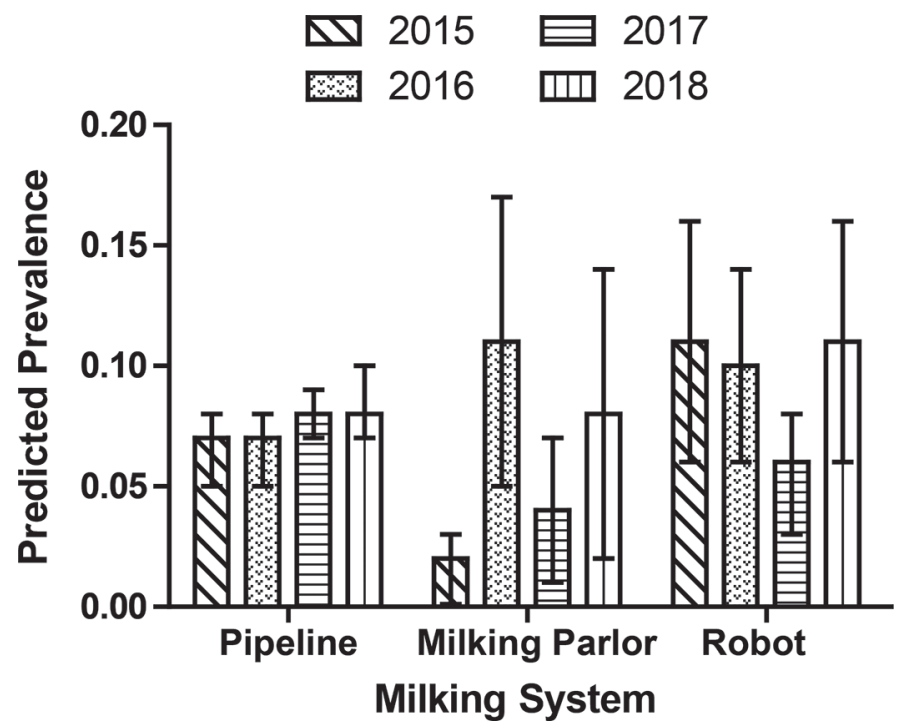

Figure 8. Predicted prevalence (marginal predicted mean probabilities) and $95 \%$ confidence intervals of heel erosion by milking system and year of the visit. Estimates were obtained using a generalized linear mixed model on data from hoof-trimming sessions performed in Québec dairy herds from March 2015 to July 2018. Data included 52,427 observations performed on 28,470 cows from 355 herds.

ever, the effect of age of the cow on the prevalence of any type of lesion was more important among cows housed in tiestall configurations, while the prevalence of infectious diseases seemed not to be affected by age in loose housing systems. Even if these findings are interesting, the age of the cow is not a risk factor that can be controlled in prevention and control programs.

Average Daily Milk Production. In our study, the prevalence of white line disease and hemorrhages increased drastically after an average herd daily production of $25 \mathrm{~kg} /$ cow per day for cows milked in milking parlors. These results agree with a previous study based in the United Kingdom in which high-producing cows were more likely to develop noninfectious foot diseases (e.g., white line disease and sole ulcer; Amory et al., 2008). However, our results for other milking systems do not agree with Amory et al. (2008). The prevalence of white line disease was inversely related to average daily production in pipeline systems, and the prevalence of hemorrhages was only slightly affected by average herd daily production in cows milked in robotic milking systems. In Amory et al. (2008), the type of housing or milking system of the 30 farms included was not mentioned. As opposed to milking parlors, cows in pipeline and robotic milking systems are less likely to be exposed to prolonged standing and mechanical stresses in the milking holding area that may favor the development of foot-horn-associated diseases (Greenough, 2007; Shearer and van Amstel, 2017).

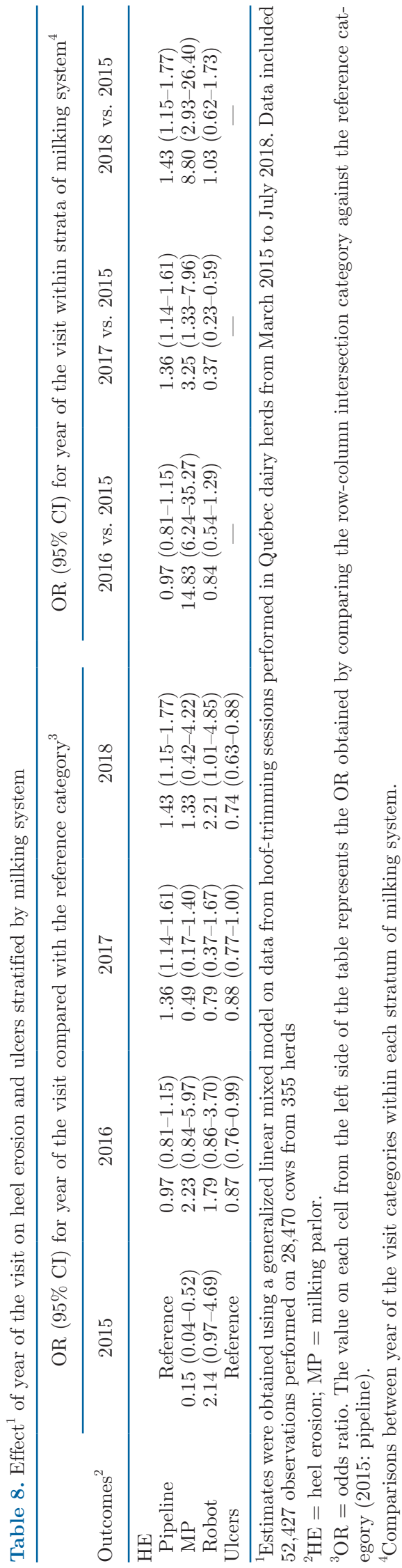


Previous studies suggest that milk production is not likely to have an effect on infectious foot diseases (Amory et al., 2008; Oberbauer et al., 2013). In our study, no effect of average herd daily production on the prevalence of infectious diseases was observed among cows milked in pipeline and robotic systems. However, among cows milked in milking parlors, the prevalence of infectious diseases was higher for cows originating from herds where the average daily production was $\leq 27 \mathrm{~kg} /$ cow per day (i.e., low average herd daily production). The association observed, however, could be one of reverse causation. Cows with infectious diseases could consequently have reduced milk production, especially if they have to move around for feeding (i.e., in loose housing systems). Consequently, it would make sense to have a lower herd average milk production in herds where many cows are affected by infectious foot lesions. However, the association between herd average milk production and probability of infectious disease was not as striking in robotic milking herds. We hypothesize that a cow affected by an infectious foot lesion may choose to spend as little time standing as possible. In herds using milking parlors, the period of time spent standing before each milking for these cows may compete with the time they will choose to spend standing while feeding. On the other hand, in a robotic milking herd, most of the standing time available could be spent on feeding, thus mitigating the effect of infectious foot lesions on the milk production of the cow (and then the herd).

Year of the Visit. In addition to the slight increase in the prevalence of heel erosion observed during the study period for cows milked using pipeline milking systems, no other particular striking pattern was observed. Nevertheless, the present study was not designed to assess the change in the prevalence of foot lesions after an intervention, but to quantify the prevalence from observations made during trimming sessions.

Breed. In our study, the effect of some predictors (e.g., breed and herd size) on the prevalence of foot lesions did not vary across milking systems (i.e., an interaction between the predictors and milking system was not observed).

Our results suggest a lower prevalence of foot lesions for cows of other breeds compared with Holstein, regardless of the housing conditions of the cows. Other studies have also found differences in foot lesion prevalence by breed. One study analyzing data collected during regular trimming sessions performed in 1,449 cows originating from 78 herds in Switzerland reported lower within-herd prevalence of foot lesions in Brown Swiss herds compared with Holstein herds (Becker et al., 2014b). A lower risk of white line disease and sole ulcers in Ayrshire cows compared with Holstein was reported in 2 other studies conducted in Finland that analyzed data collected from regular trimming sessions performed in 16,792 cows originating from 703 herds (Kujala et al., 2009; Kujala et al., 2010). Similar to age of the cow, breed cannot be easily modified in prevention and control programs, provided that the goal of dairy industry is producing milk and Holstein is the most productive breed. It has been suggested that high-producing cows have a greater risk of developing metabolic diseases (Gröhn et al., 1999), which may predispose them to lameness because of the negative effect of metabolic imbalances on foot-horn health (Mülling et al., 1999).

Herd Size. The effect of herd size on the prevalence of infectious diseases and heel erosion did not vary, regardless of the milking system. Originating form a large herd ( $>65$ cows) increased the odds of infectious diseases and heel erosion, while the odds of hemorrhages were inversely related to herd size.

\section{Study Validity and Limitations}

We believe that the present study is representative of Québec dairy cows and herds because the study population represented $8 \%$ and $7 \%$ of the cows and herds of Québec, respectively. To ensure that the analyzed data corresponded to regular trimming sessions, only data collected during trimming sessions where at least $90 \%$ of the lactating herd was trimmed were studied. Data obtained during regular trimming sessions are a reliable source of information for describing foot health (Heringstad et al., 2018). However, it is possible that, in some large dairy farms, trimming of the entire herd is programmed in sessions scheduled more than $30 \mathrm{~d}$ apart (i.e., having half of the herd trimmed on a given day and the other half 6 mo later). Inadvertently excluding many regular preventive trimming sessions in which less than $90 \%$ of the herd was trimmed would only reduce sample size, and thus the power of the present study, rather than introduce any bias.

Variation between hoof trimmers has been shown to have an effect on the classification of lesions (Holzhauer et al., 2006; Cramer et al., 2018), but could not be investigated in the current study. Moreover, in the DHI database used for the current study, hoof trimmer identification was not retained to preserve confidentiality; therefore, it was not possible to investigate whether prevalence of foot lesions reported differed between hoof trimmers. To ensure consistency of foot-lesions recording, hoof trimmers who participated in the present study were retrained annually on lesion identification. Moreover, they all belonged to the same professional 
hoof trimmers association, and thus were more likely to report lesions in a uniform manner. Nevertheless, we hypothesized that the fading prevalence observed from 2015 to 2018 for some lesions may be explained, in part, by a fading interest for reporting some of these lesions. With the current study design, however, we could not differentiate whether the fading prevalence resulted from a true reduction in foot lesions incidence (because of increase awareness from the industry), reduced reporting by trimmers, or both. On the other hand, a decreasing interest for reporting would be generalized across herd- (e.g., type of milking systems, herd size) and cow-level characteristics (e.g., breed, parity). This pattern of misclassification is known as nondifferential misclassification (i.e., an imperfect reporting of the outcome that is unlikely to be associated with the exposition). A previous study demonstrated that for diseases with prevalence $<20 \%$ (similar to most foot lesions), this type of bias would have very little effect on measures of disease frequency and of association with exposures, even for diagnostic tests with moderate sensitivity (e.g., 80\%), as long as the specificity of the diagnostic test remains high (Haine et al., 2018). In our case, this means that as long as our hoof trimmers were not classifying healthy cows as diseased, and even if they underreported some of the lesions, our estimates of foot lesions prevalence and of association between herd- and cow-level predictors and probability of lesions would be unbiased.

Finally, in the current study we did not describe foot lesions prevalence as a function of DIM or season. Our future research will investigate evolution of lesions over time and effect of the different lesions on milk yield, culling, and fertility. In these future analyses, the production cycle and seasonal components will be investigated using proportional hazard models. This will allow for describing how lesions develop (i.e., incidence data) as a function of the cow production cycle.

\section{CONCLUSIONS}

About $29 \%$ of the cows examined during regular trimming sessions in Québec presented at least 1 foot lesion. When analyzed by milking system, prevalence estimates for at least 1 foot lesion were 27, 38, and $41 \%$ for cows milked in pipeline, robotic milking, and milking parlors, respectively. Infectious disease had the highest prevalence in milking parlors and robotic systems, while hemorrhage was the most prevalent lesion in pipeline systems. Our results suggest that control measures to reduce the prevalence of infectious diseases, heel erosion, and hemorrhages should be implemented at the herd level.

\section{ACKNOWLEDGMENTS}

The authors acknowledge Les Producteurs de lait du Québec (Longueuil, QC, Canada), Association des pareurs d'onglons du Québec (Notre-Dame-du-BonConseil, QC, Canada), and Lactanet (Sainte-Annede-Bellevue, QC, Canada). This project was funded by Agriculture and Agri-Food Canada (Ottawa, ON, Canada) and the Ministère de l'Agriculture, des Pêcheries et de l'Alimentation du Québec (MAPAQ; Québec, QC, Canada) under the Programme de soutien aux stratégies sectorielles de développement 2 . The authors have no conflicts of interest to declare.

\section{REFERENCES}

Amory, J. R., Z. E. Barker, J. L. Wright, S. A. Mason, R. W. Blowey, and L. E. Green. 2008. Associations between sole ulcer, white line disease and digital dermatitis and the milk yield of 1,824 dairy cows on 30 dairy cow farms in England and Wales from February 2003-November 2004. Prev. Vet. Med. 83:381-391. https://doi .org/10.1016/j.prevetmed.2007.09.007.

Archer, S. C., M. J. Green, and J. N. Huxley. 2010. Association between milk yield and serial locomotion score assessments in UK dairy cows. J. Dairy Sci. 93:4045-4053. https://doi.org/10.3168/ jds.2010-3062.

Barkema, H. W., J. D. Westrik, K. A. S. van Keulen, Y. H. Schukken, and A. Brand. 1994. The effects of lameness on reproductive performance, milk production and culling in Dutch dairy farms. Prev. Vet. Med. 20:249-259. https://doi.org/10.1016/0167 -5877(94)90058-2.

Becker, J., A. Steiner, S. Kohler, A. Koller-Bahler, M. Wuthrich, and M. Reist. 2014a. Lameness and foot lesions in Swiss dairy cows: I. Prevalence. Schweiz. Arch. Tierheilkd. 156:71-78. https://doi.org/ 10.1024/0036-7281/a000553.

Becker, J., A. Steiner, S. Kohler, A. Koller-Bahler, M. Wuthrich, and M. Reist. 2014b. Lameness and foot lesions in Swiss dairy cows: II. Risk factors. Schweiz. Arch. Tierheilkd. 156:79-89. https://doi .org/10.1024/0036-7281/a000554.

Bell, N. J., M. J. Bell, T. G. Knowles, H. R. Whay, D. J. Main, and A. J. Webster. 2009. The development, implementation and testing of a lameness control programme based on HACCP principles and designed for heifers on dairy farms. Vet. J. 180:178-188. https:// doi.org/10.1016/j.tvjl.2008.05.020.

Berry, S. L. 2001. Diseases of the digital soft tissues. Vet. Clin. North Am. Food Anim. Pract. 17:129-142. https://doi.org/10.1016/ S0749-0720(15)30058-X.

Bicalho, R. C., V. S. Machado, and L. S. Caixeta. 2009. Lameness in dairy cattle: A debilitating disease or a disease of debilitated cattle? A cross-sectional study of lameness prevalence and thickness of the digital cushion. J. Dairy Sci. 92:3175-3184. https://doi .org/10.3168/jds.2008-1827.

Borderas, T. F., B. Pawluczuk, A. M. de Passille, and J. Rushen. 2004. Claw hardness of dairy cows: Relationship to water content and claw lesions. J. Dairy Sci. 87:2085-2093. https://doi.org/10.3168/ jds.S0022-0302(04)70026-0.

Canadian Dairy Information Center. Government of Canada. 2018. Dairy barns by type in Canada. Accessed Aug. 24, 2019. http:// www.dairyinfo.gc.ca/index_e.php?s1=dff-fcil\&s2=farm-ferme\&s3 $=\mathrm{db}-\mathrm{el}$

Cha, E., J. A. Hertl, D. Bar, and Y. T. Grohn. 2010. The cost of different types of lameness in dairy cows calculated by dynamic programming. Prev. Vet. Med. 97:1-8. https://doi.org/10.1016/j .prevetmed.2010.07.011.

Charfeddine, N., and M. A. Pérez-Cabal. 2017. Effect of claw disorders on milk production, fertility, and longevity, and their economic 
impact in Spanish Holstein cows. J. Dairy Sci. 100:653-665. https: //doi.org/10.3168/jds.2016-11434.

Christen, A. M., and A. Desrochers. 2015. Le parage des onglons au Québec en 2015. Progressive Dairy en français 2:28-31.

Cramer, G., K. D. Lissemore, C. L. Guard, K. E. Leslie, and D. F. Kelton. 2008. Herd- and cow-level prevalence of foot lesions in Ontario dairy cattle. J. Dairy Sci. 91:3888-3895. https://doi.org/ 10.3168/jds.2008-1135.

Cramer, G., T. Winders, L. Solano, and D. H. Kleinschmit. 2018. Evaluation of agreement among digital dermatitis scoring methods in the milking parlor, pen, and hoof trimming chute. J. Dairy Sci. 101:2406-2414. https://doi.org/10.3168/jds.2017-13755.

DeFrain, J. M., M. T. Socha, and D. J. Tomlinson. 2013. Analysis of foot health records from 17 confinement dairies. J. Dairy Sci. 96:7329-7339. https://doi.org/10.3168/jds.2012-6017.

Dohoo, I. R., C. Ducrot, C. Fourichon, A. Donald, and D. Hurnik. 1997. An overview of techniques for dealing with large numbers of independent variables in epidemiologic studies. Prev. Vet. Med. 29:221-239. https://doi.org/10.1016/S0167-5877(96)01074-4.

Flower, F. C., and D. M. Weary. 2009. Gait assessment in dairy cattle. Animal 3:87-95. https://doi.org/10.1017/S1751731108003194.

Goldstein, H., W. Browne, and J. Rasbash. 2002. Partitioning variation in multilevel models. Underst. Stat. 1:223-231. https://doi .org/10.1207/S15328031US0104_02.

Green, L. E., V. J. Hedges, Y. H. Schukken, R. W. Blowey, and A. J. Packington. 2002. The impact of clinical lameness on the milk yield of dairy cows. J. Dairy Sci. 85:2250-2256. https://doi.org/10 $.3168 /$ jds.S0022-0302(02)74304-X.

Greenough, P. R. 2007. Bovine laminitis and lameness: A hands on approach. Saunders/Elsevier, Edinburgh, New York.

Gröhn, Y. T., J. J. McDermott, Y. H. Schukken, J. A. Hertl, and S. W. Eicker. 1999. Analysis of correlated continuous repeated observations: modelling the effect of ketosis on milk yield in dairy cows. Prev. Vet. Med. 39:137-153. https://doi.org/10.1016/S0167 $-5877(98) 00145-7$.

Haine, D., I. Dohoo, and S. Dufour. 2018. Selection and misclassification biases in longitudinal studies. Front. Vet. Sci. 5:99. https:// doi.org/10.3389/fvets.2018.00099.

Heringstad, B., C. Egger-Danner, N. Charfeddine, J. E. Pryce, K. F. Stock, J. Kofler, A. M. Sogstad, M. Holzhauer, A. Fiedler, K. Muller, P. Nielsen, G. Thomas, N. Gengler, G. de Jong, C. Odegard, F. Malchiodi, F. Miglior, M. Alsaaod, and J. B. Cole. 2018. Invited review: Genetics and claw health: Opportunities to enhance claw health by genetic selection. J. Dairy Sci. 101:48014821. https://doi.org/10.3168/jds.2017-13531.

Holzhauer, M., C. J. Bartels, B. H. van den Borne, and G. van Schaik. 2006. Intra-class correlation attributable to claw trimmers scoring common hind-claw disorders in Dutch dairy herds. Prev. Vet. Med. 75:47-55. https://doi.org/10.1016/j.prevetmed.2006.01.013.

Knol, M. J., and T. J. VanderWeele. 2012. Recommendations for presenting analyses of effect modification and interaction. Int. J. Epidemiol. 41:514-520. https://doi.org/10.1093/ije/dyr218.

Kujala, M., I. R. Dohoo, M. Laakso, C. Schnier, and T. Soveri. 2009. Sole ulcers in Finnish dairy cattle. Prev. Vet. Med. 89:227-236. https://doi.org/10.1016/j.prevetmed.2009.02.007.

Kujala, M., I. R. Dohoo, and T. Soveri. 2010. White-line disease and haemorrhages in hooves of Finnish dairy cattle. Prev. Vet. Med. 94:18-27. https://doi.org/10.1016/j.prevetmed.2009.12.006.
Lacroix, R., D. Santshi, M. Duplessis, D. Lefebvre, and R. Cue. 2014 Réduire l'âge au premier vêlage par l'adoption d'un outil pratique de suivi de croissance des génisses. https://www.mapaq.gouv.qc .ca/SiteCollectionDocuments/Recherche_Innovation/Bovins/ 211023.pdf

Liang, D., L. M. Arnold, C. J. Stowe, R. J. Harmon, and J. M. Bewley. 2017. Estimating US dairy clinical disease costs with a stochastic simulation model. J. Dairy Sci. 100:1472-1486. https://doi.org/10 .3168/jds.2016-11565.

Mülling, C. K., H. H. Bragulla, S. Reese, K. D. Budras, and W. Steinberg. 1999. How structures in bovine hoof epidermis are influenced by nutritional factors. Anat. Histol. Embryol. 28:103-108. https:/ /doi.org/10.1046/j.1439-0264.1999.00180.x.

Oberbauer, A. M., S. L. Berry, J. M. Belanger, R. M. McGoldrick, J. M. Pinos-Rodriquez, and T. R. Famula. 2013. Determining the heritable component of dairy cattle foot lesions. J. Dairy Sci. https://doi.org/10.3168/jds.2012-5485.

Sanders, A. H., J. K. Shearer, and A. De Vries. 2009. Seasonal incidence of lameness and risk factors associated with thin soles, white line disease, ulcers, and sole punctures in dairy cattle. J. Dairy Sci. 92:3165-3174. https://doi.org/10.3168/jds.2008-1799.

Shearer, J., D. Anderson, W. Ayars, E. Belknap, S. Berry, C. Guard, K. Hoblet, E. Hovingh, G. Kirksey, and A. Langill. 2004. A recordkeeping system for capture of lameness and foot-care information in cattle. Bov. Pract. 38:83-92.

Shearer, J. K., and S. R. van Amstel. 2017. Pathogenesis and treatment of sole ulcers and white line disease. Vet. Clin. North Am. Food Anim. Pract. 33:283-300. https://doi.org/10.1016/j.cvfa .2017.03.001.

Solano, L., H. W. Barkema, S. Mason, E. A. Pajor, S. J. LeBlanc, and K. Orsel. 2016. Prevalence and distribution of foot lesions in dairy cattle in Alberta, Canada. J. Dairy Sci. 99:6828-6841. https://doi .org/10.3168/jds.2016-10941.

Somers, J. G., K. Frankena, E. N. Noordhuizen-Stassen, and J. H. Metz. 2003. Prevalence of claw disorders in Dutch dairy cows exposed to several floor systems. J. Dairy Sci. 86:2082-2093. https: /doi.org/10.3168/jds.S0022-0302(03)73797-7.

The Alberta Dairy Hoof Health Project. 2014. Pages 1-42 in Lesion Severity Scoring Guide. The Alberta Dairy Hoof Health Project, Alberta, Canada.

von Keyserlingk, M. A., J. Rushen, A. M. de Passille, and D. M. Weary. 2009. Invited review: The welfare of dairy cattle-Key concepts and the role of science. J. Dairy Sci. 92:4101-4111. https:// doi.org/10.3168/jds.2009-2326.

Whay, H. R., and J. K. Shearer. 2017. The impact of lameness on welfare of the dairy cow. Vet. Clin. North Am. Food Anim. Pract. 33:153-164. https://doi.org/10.1016/j.cvfa.2017.02.008.

\section{ORCIDS}

Juan C. Arango-Sabogal ๑ https://orcid.org/0000-0003-3395-8410

André Desrochers @ (ㄴ) https://orcid.org/0000-0002-0568-4478

René Lacroix @ https://orcid.org/0000-0002-8618-022X

Anne-Marie Christen (ㄴ) https://orcid.org/0000-0003-4537-9846

Simon Dufour @ https://orcid.org/0000-0001-6418-0424 